\title{
Implementasi Data Mining Menggunakan Algoritma Apriori Pada Penjualan Suku Cadang Motor
}

\author{
Ainul Mardiaha1, Yulia ${ }^{\mathrm{a} 2}$ \\ aUniversitas Putera Batam, Teknik Informatika \\ Jln. R. Soeprapto, Muka Kuning, Batam, Indonesia \\ 1ainulrasfi02@gmail.com \\ 2yuliaedwar2407@gmail.com
}

\begin{abstract}
This research was carried out to simplify or assist Candra Motor workshop owners in managing data and archives of motorcycle parts sales by applying a data mining a priori algorithm method. Data mining is an operation that uses a particular technique or method to look for different patterns or shapes in a selected data. Sales data for a year with the number of 15 items selected using the priori algorithm method. A priori algorithm is an algorithm for taking data with associative rules (association rule) to determine the associative relationship of an item combination. In a priori algorithm, it is determined frequent itemset-1, frequent itemset-2, and frequent itemset-3 so that the association rules can be obtained from previously selected data. To obtain the frequent itemset, each selected data must meet the minimum support and minimum confidence requirements. In this study using minimum support $\geq 7$ or 0.583 and minimum confidence of $90 \%$. So that some rules of association were obtained, where the calculation of the search for association rules manually and using WEKA software obtained the same results.By fulfilling the minimum support and minimum confidence requirements, the most sold spare parts are inner tube, Yamaha oil and MPX oil.
\end{abstract}

Keywords: Data Mining, Motor Parts Sales, Apriori Algorithms

\section{Pendahuluan}

Berbicara mengenai segala hal yang berhubungan dengan perkembangan teknologi tidak akan ada habis-habisnya sama sekali. Setiap tahunnya pasti akan mengalami perkembangan, dimana perkembangan dari teknologi tersebut memiliki tujuan agar tercipta suatu teknologi yang lebih baik lagi dan bisa membuat perubahan dalam mempermudah semua tugas termasuk dalam pengolahan data penjualan. Salah satu teknologi yang banyak digunakan oleh masyarakat untuk membantu mempermudah pekerjaan mereka dalam pengolahan data penjualan adalah data mining [1].

Setiap aktivitas penjualan memiliki banyak data yang harus diolah agar data tersebut menjadi bermanfaat dan tidak hanya menjadi tumpukan data saja. Salah satu tempat yang selalu melakukan banyak transaksi penjualan adalah bengkel motor. Bengkel motor merupakan tempat penyedia jasa service motor serta penjualan suku cadang motor [2]. Bengkel bergerak dibidang dunia bisnis, dimana yang setiap harinya akan terjadi transaksi, baik transaksi service motor ataupun penjualan suku cadang motor. Karena setiap harinya terjadi transaksi penjualan, maka kemungkinan besar data transaksi yang diperoleh akan sangat banyak dan menumpuk. Data transaksi yang diperoleh sering kali hanya digunakan sebagai arsip ataupun bukti penjualan, selain itu data tersebut sudah tidak memiliki fungsi lagi bagi bengkel tersebut, maka data tersebut hanya akan menjadi tumpukan data yang tidak berguna. Dengan adanya perkembangan teknologi, maka data tersebut dapat memberi keuntungan bagi bengkel Candra Motor agar dapat meminimalisir waktu kerja pengguna data mining [3].

Data mining adalah suatu operasi yang menggunakan teknik atau metode tertentu untuk mencari pola atau bentuk yang berbeda dalam sebuah data yang terpilih [4]. Penelitian 
data mining ini menggunakan algoritma apriori. Algoritma apriori adalah algoritma pengambilan data dengan aturan asosiatif (association rule) untuk menentukan hubungan asosiatif suatu kombinasi item. Association rule yang dimaksud dilakukan melalui mekanisme penghitungan support dan confidence dari suatu hubungan item [5]. Jika strategi penjualan suku cadang motor tidak direncanakan dengan baik dan benar, maka strategi penjualan suku cadang motor tersebut akan membutuhkan waktu yang lama atau menghabiskan banyak waktu, biaya dan tenaga. Dengan adanya bantuan perkembangan teknologi seharusnya bisa meminimalisir waktu, biaya dan tenaga manusia yang digunakan. Misalnya mempermudah pekerjaan untuk mengetahui barang apa saja yang dibeli oleh para konsumen, sehingga waktu pelayanan terhadap konsumen menjadi lebih efektif. Salah satunya adalah dengan mengimplementasikan penggunaan data mining [6].

\section{Metodologi Penelitian}

\subsection{Desain Penelitian}

Dalam melakukan suatu penelitian, sangat diperlukan suatu perencanaan ataupun perancangan penelitian, agar penelitian tersebut dapat berjalan dengan baik dan sistematis. Suatu perencanaan ataupun perancangan penelitian tentang data mining ini dipresentasikan di dalam sebuah desain penelitian yang dijelaskan pada gambar 1 berikut.

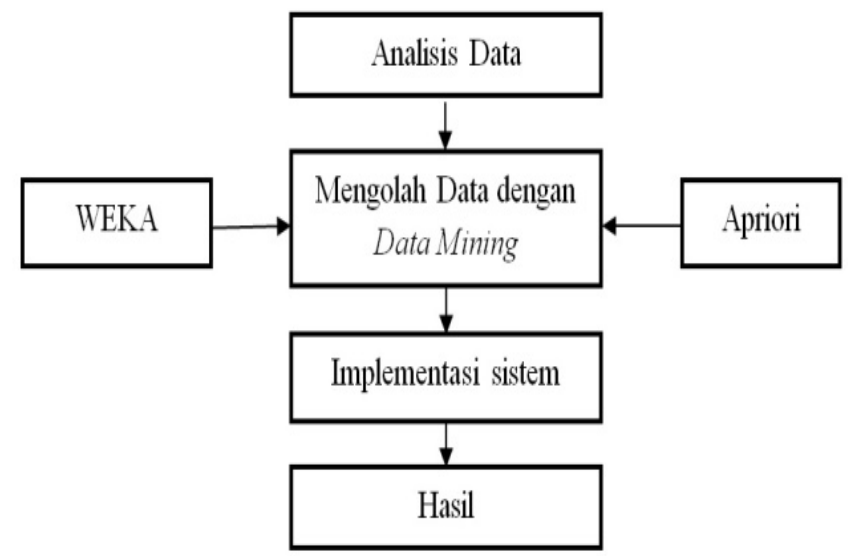

Gambar 1. Desain Penelitian

a)

Tahapan-tahapan penelitian sebagai berikut :

\section{Analisis Data}

Setelah data selesai diseleksi, kemudian data dianalisis kembali, agar data yang diperoleh lebih akurat. Data yang digunakan adalah data transaksi penjualan suku cadang motor di bengkel candra dari transaksi barang yang banyak terjual.

b) Mengolah Data dengan data mining

Data-data yang sudah dianalisis kemudian diolah menggunakan data mining dengan algoritma apriori sehingga mendapatkan rule assosiasi. Pada tahap ini akan dilakukan perhitungan nilai support dan confidence dan akan dilihat apakah pada frequent tersebut dapat memenuhi syarat minimum support dan syarat minimum confidence [7].

$$
\begin{aligned}
& \text { Support }(A)=\frac{\text { Jumlah transaksi mengandung } A}{\text { Total Transaksi }} \\
& \text { Confidence }=P(B \mid A)=\frac{\sum \text { Transaksi mengandung A dan B }}{\sum \text { Transaksi mengandung } A}
\end{aligned}
$$

c) Implementasi Sistem

Pengujian data yang dilakukan dengan aplikasi WEKA, untuk memperoleh kecocokan data yang diolah secara manual dengan sistem. 
d) Hasil

Dari semua proses yang sudah dilakukan maka diperoleh suatu hasil dari data penelitian tersebut berupa item set yang paling banyak terjual. Sehingga terbentuk rule assosiasi dari penjualan suku cadang motor.

\subsection{Operasional Variabel}

Menurut [8] definisi operasional adalah penentuan data atau sifat yang akan dipelajari sehingga menjadi variabel yang dapat diukur. Definisi operasional menjelaskan cara tertentu yang digunakan untuk meneliti dan mengoperasikan konstrak, sehingga memungkinkan bagi peneliti yang lain untuk melakukan replikasi pengukuran dengan cara yang sama atau mengembangkan cara pengukuran konstrak yang lebih baik. Adapun variabel-variabel yang diambil sebagai sumber data adalah sebagai berikut :

a) Jumlah Transaksi Jumlah transaksi yaitu banyaknya jumlah penjualan stok suku cadang motor dalam kurun waktu perbulan selama setahun terakhir. Dari data jumlah transaksi ini dapat menentukan item set yang paling banyak terjual.

b) Nama Suku Cadang Motor

Nama suku cadang motor merupakan nama-nama produk ataupun barang yang tersedia di bengkel Candra Motor dan produk atau barang mana saja yang paling banyak terjual. Adapun nama-nama produk atau barang yang tersedia adalah oli mesin, oli samping, ban dalam, ban luar, kampas rem belakang, dll.

\subsection{Metode Analisis dan Perancangan Sistem}

a) Metode Analisis

Metode analisis merupakan suatu hal yang terpenting dalam melakukan sebuah penelitian. Jika metode sebuah penelitian tidak mempunyai metode analisis, maka keakuratan hasil dari sebuah penelitian tersebut masih diragukan. Metode analisis sangat mempengaruhi hasil dari sebuah penelitian tersebut. Sehingga pada penelitian ini menggunakan data mining dengan metode apriori.

b) Perancangan Sistem

Adapun metode perancangan sistem yang digunakan dapat dijelaskan pada gambar yang di bawah ini.

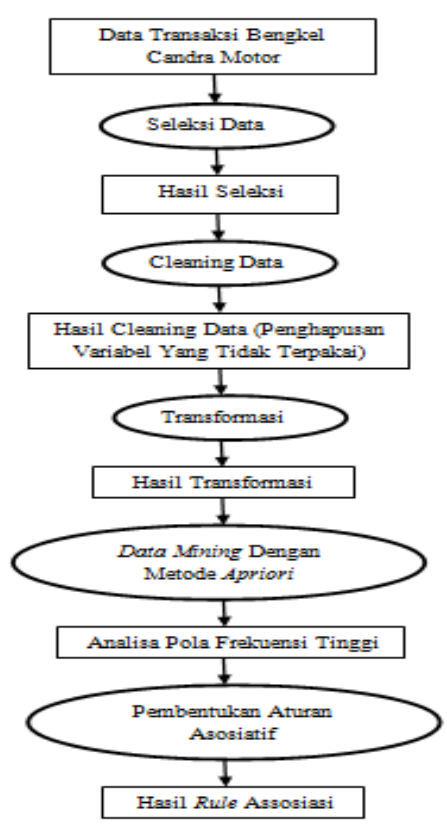

Gambar 2. Perancangan Sistem 
Pada gambar 2 dapat dijelaskan bahwa mengumpulkan data penjualan suku cadang pada bengkel Candra Motor akan dilakukan seleksi data untuk memilih data yang layak untuk dijadikan sampel. Data yang digunakan adalah penjualan perhari, perbulan, pertahun kemudian akan diolah menggunakan algoritma apriori dan dan diimplementasikan dengan aplikasi WEKA.

\section{Hasil dan Pembahasan}

\subsection{Analisa Data}

Bengkel merupakan tempat yang menyediakan jasa perbaikan (service) motor serta penjualan berbagai suku cadang motor. Pada bengkel Candra Motor, data transaksi penjualan item suku cadang motor akan diolah dengan data mining algoritma apriori yang akan menemukan item suku cadang motor yang paling sering terjual. Adapun jenis suku cadang motor yang dijual dapat dikelompokkan menjadi beberapa macam. Jenis suku cadang motor tersebut dapat dilihat pada tabel 1 berikut.

Tabel 1. Daftar Item suku cadang motor

\begin{tabular}{clc}
\hline No. & \multicolumn{1}{c}{ Nama ltem } & Kode \\
\hline 1 & Ban Dalam & BD \\
2 & Kampas Kramol & KK \\
3 & Oli Mestran & OM \\
4 & Kampas & K \\
5 & Kain Jok & KJ \\
6 & Oli Gerbok & OG \\
7 & Batu Arang Stater & BAS \\
8 & Oli Castrol & OC \\
9 & Oli MPX & OMP \\
10 & Kampas Cakram & KC \\
11 & Bola Lampu & BL \\
12 & Oli Yamalub & OY \\
13 & Busi & B \\
14 & Oli Ultratec & OU \\
15 & Aki Air & AA \\
16 & Sel Sock & SS \\
17 & Rantai & R \\
18 & Oli SGO & OS \\
19 & Oli TOP1 & OT \\
\hline
\end{tabular}

Pada Daftar item suku cadang motor pada tabel 1 di atas adalah data awal yang akan dipakai dalam transaksi penjualan suku cadang motor. Sampel yang digunakan sebanyak 12 transaksi penjualan suku cadang motor, data yang diambil adalah item yang terjual $>6$ perbulannya. Transaksi penjualan suku cadang motor dapat dilihat pada tabel 2 berikut. 
Tabel 2. Data Set Awal Penjualan Suku Cadang Motor

\begin{tabular}{cll}
\hline No & \multicolumn{1}{c}{ Transaksi } & \multicolumn{1}{c}{ Suku Cadang } \\
\hline 1 & Juni & BD, OM, K, KJ, OG, OC, OMP, KC, BL, OY, B \\
2 & Juli & BD, KK, K, OG, OMP, OY, B, OU, OS \\
3 & Agustus & BD, KK, OM, K, KJ, OG, OC, OMP, KC, OY, \\
4 & September & BD, OM, KJ, OG, OC, OMP, OY, \\
5 & Oktober & BD, KK, OM, K, KJ, OG, OMP, KC, BL, OY, B, R, OS \\
6 & November & BD, OM, K, OG, OMP, BL, OY, B, \\
7 & Desember & BD, OM, K, OG, OMP, KC, BL, OY, B, R \\
8 & Januari & BD, OG, OMP, OY \\
9 & Februari & BD, KK, OM, OG, OMP, KC, OY, B \\
10 & Maret & BD, KK, OM, OG, OMP, OY, B \\
11 & April & BD, OMP, OY, B \\
12 & Mei & OMP \\
\hline
\end{tabular}

Setelah data set awal penjualan suku cadang motor sudah dikelompokkan ke dalam sebuah tabel, untuk lebih mempermudah data dapat dibaca maka jenis transaksi akan diberikan kode pada setiap transaksi, adapun kode tersebut dapat dilihat pada tabel 3 berikut.

Tabel 3. Kode Transaksi

\begin{tabular}{ccc}
\hline No. & Transaksi & Kode \\
\hline 1 & Januari & Jan \\
2 & Februari & Feb \\
3 & Maret & Mar \\
4 & April & Apr \\
5 & Mei & Mei \\
6 & Juni & Jun \\
7 & Juli & Jul \\
8 & Agustus & Agus \\
9 & September & Sept \\
10 & Oktober & Okt \\
11 & November & Nov \\
12 & Desember & Des \\
\hline
\end{tabular}

Di dalam sebuah proses KDD tahapan awalnya adalah pembersihan data (data cleaning), pembersihan data (data cleaning) sudah selesai dilakukan pada tahapan sebelumnya [9]. Setelah data cleaning, maka tahapan berikutnya adalah integrasi data (penggabungan data dari beberapa penjualan). Hasil dari integrasi data transaksi dapat dilihat pada tabel 4 di bawah ini.

Tabel 4. Hasil integrasi data transaksi

\begin{tabular}{cccccccccccccccc}
\hline Transaksi & BD & KK & OM & K & KJ & OG & OC & OMP & KC & BL & OY & B & OU & R & OS \\
\hline Jun & Y & N & Y & Y & Y & Y & Y & Y & Y & Y & Y & Y & N & N & N \\
Jul & $\mathrm{Y}$ & $\mathrm{Y}$ & $\mathrm{N}$ & $\mathrm{Y}$ & $\mathrm{N}$ & $\mathrm{Y}$ & $\mathrm{N}$ & $\mathrm{Y}$ & $\mathrm{N}$ & $\mathrm{N}$ & $\mathrm{Y}$ & $\mathrm{Y}$ & $\mathrm{Y}$ & $\mathrm{N}$ & $\mathrm{Y}$ \\
Agus & $\mathrm{Y}$ & $\mathrm{Y}$ & $\mathrm{Y}$ & $\mathrm{Y}$ & $\mathrm{Y}$ & $\mathrm{Y}$ & $\mathrm{Y}$ & $\mathrm{Y}$ & $\mathrm{Y}$ & $\mathrm{N}$ & $\mathrm{Y}$ & $\mathrm{N}$ & $\mathrm{N}$ & $\mathrm{N}$ & $\mathrm{N}$ \\
Sept & $\mathrm{Y}$ & $\mathrm{N}$ & $\mathrm{Y}$ & $\mathrm{N}$ & $\mathrm{Y}$ & $\mathrm{Y}$ & $\mathrm{Y}$ & $\mathrm{Y}$ & $\mathrm{N}$ & $\mathrm{N}$ & $\mathrm{Y}$ & $\mathrm{N}$ & $\mathrm{N}$ & $\mathrm{N}$ & $\mathrm{N}$ \\
Okt & $\mathrm{Y}$ & $\mathrm{Y}$ & $\mathrm{Y}$ & $\mathrm{Y}$ & $\mathrm{Y}$ & $\mathrm{Y}$ & $\mathrm{N}$ & $\mathrm{Y}$ & $\mathrm{Y}$ & $\mathrm{Y}$ & $\mathrm{Y}$ & $\mathrm{Y}$ & $\mathrm{N}$ & $\mathrm{Y}$ & $\mathrm{Y}$
\end{tabular}




\begin{tabular}{lllllllllllllllll} 
Nov & $\mathrm{Y}$ & $\mathrm{N}$ & $\mathrm{Y}$ & $\mathrm{Y}$ & $\mathrm{N}$ & $\mathrm{Y}$ & $\mathrm{N}$ & $\mathrm{Y}$ & $\mathrm{N}$ & $\mathrm{Y}$ & $\mathrm{Y}$ & $\mathrm{Y}$ & $\mathrm{N}$ & $\mathrm{N}$ & $\mathrm{N}$ \\
Des & $\mathrm{Y}$ & $\mathrm{N}$ & $\mathrm{Y}$ & $\mathrm{Y}$ & $\mathrm{N}$ & $\mathrm{Y}$ & $\mathrm{N}$ & $\mathrm{Y}$ & $\mathrm{Y}$ & $\mathrm{Y}$ & $\mathrm{Y}$ & $\mathrm{Y}$ & $\mathrm{N}$ & $\mathrm{Y}$ & $\mathrm{N}$ \\
Jan & $\mathrm{Y}$ & $\mathrm{N}$ & $\mathrm{N}$ & $\mathrm{N}$ & $\mathrm{N}$ & $\mathrm{Y}$ & $\mathrm{N}$ & $\mathrm{Y}$ & $\mathrm{N}$ & $\mathrm{N}$ & $\mathrm{Y}$ & $\mathrm{N}$ & $\mathrm{N}$ & $\mathrm{N}$ & $\mathrm{N}$ \\
Feb & $\mathrm{Y}$ & $\mathrm{Y}$ & $\mathrm{Y}$ & $\mathrm{N}$ & $\mathrm{N}$ & $\mathrm{Y}$ & $\mathrm{N}$ & $\mathrm{Y}$ & $\mathrm{Y}$ & $\mathrm{N}$ & $\mathrm{Y}$ & $\mathrm{Y}$ & $\mathrm{N}$ & $\mathrm{N}$ & $\mathrm{N}$ \\
Mar & $\mathrm{Y}$ & $\mathrm{Y}$ & $\mathrm{Y}$ & $\mathrm{N}$ & $\mathrm{N}$ & $\mathrm{Y}$ & $\mathrm{N}$ & $\mathrm{Y}$ & $\mathrm{N}$ & $\mathrm{N}$ & $\mathrm{Y}$ & $\mathrm{Y}$ & $\mathrm{N}$ & $\mathrm{N}$ & $\mathrm{N}$ \\
Apr & $\mathrm{Y}$ & $\mathrm{N}$ & $\mathrm{N}$ & $\mathrm{N}$ & $\mathrm{N}$ & $\mathrm{N}$ & $\mathrm{N}$ & $\mathrm{Y}$ & $\mathrm{N}$ & $\mathrm{N}$ & $\mathrm{Y}$ & $\mathrm{Y}$ & $\mathrm{N}$ & $\mathrm{N}$ & $\mathrm{N}$ \\
Mei & $\mathrm{N}$ & $\mathrm{N}$ & $\mathrm{N}$ & $\mathrm{N}$ & $\mathrm{N}$ & $\mathrm{N}$ & $\mathrm{N}$ & $\mathrm{Y}$ & $\mathrm{N}$ & $\mathrm{N}$ & $\mathrm{N}$ & $\mathrm{N}$ & $\mathrm{N}$ & $\mathrm{N}$ & $\mathrm{N}$ \\
\hline
\end{tabular}

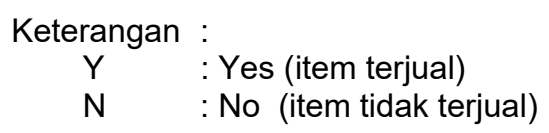

\subsection{Hasil Pengujian}

Penjualan suku cadang motor mengakumulasikan data transaksi penjualan menggunakan data mining dengan teknik association rule. Algoritma apriori digunakan untuk mencari aturan yang mempunyai support $\geq$ minsup dan confidence $\geq$ minconf, dimana minsup adalah ambang batas support, sedangkan minconf adalah ambang batas confidence [10].

\subsubsection{Pengujian Secara Manual}

Algoritma apriori menggunakan pendekatan secara interaktif yang diketahui juga dengan level-wise search dimana $k$-item digunakan untuk mencari $(\mathrm{k}+1)$ itemset . Langkah pertama adalah mencari set dari frequent 1- itemset, set ini dilambangkan sebagai $\mathrm{F} 1$ dimana F1 digunakan untuk menemukan F2, dari frequent 2- itemset, akan digunakan untuk F3 dan seterusnya sampai tidak ada lagi frequent k-itemset yang ditemukan. Proses untuk menemukan setiap frequent (Fk) dengan melakukan satu kali pemeriksaan menyeluruh pada database yang artinya apabila $k$ ada tiga atau lebih, maka pemeriksaan terhadap database dilakukan sebanyak tiga kali atau lebih sampai $k$ [11].

Dari data transaksi suku cadang motor diasumsikan frequent item $\geq 7$ atau dengan support 0,583 seperti pada tabel 5 berikut.

\begin{tabular}{cccc} 
C1 & \multicolumn{3}{c}{ Tabel 5. Frequent 1-itemset } \\
\hline No. & Itemset & Frequent Item & Support \\
\hline 1 & $\mathrm{BD}(\mathrm{Y})$ & 11 & 0.917 \\
2 & $\mathrm{BD}(\mathrm{N})$ & 1 & 0.083 \\
3 & $\mathrm{KK}(\mathrm{Y})$ & 5 & 0.417 \\
4 & $\mathrm{KK}(\mathrm{N})$ & 7 & 0.583 \\
5 & $\mathrm{OM}(\mathrm{Y})$ & 8 & 0.67 \\
6 & $\mathrm{OM}(\mathrm{N})$ & 4 & 0.33 \\
7 & $\mathrm{~K}(\mathrm{Y})$ & 6 & 0.5 \\
8 & $\mathrm{~K}(\mathrm{~N})$ & 6 & 0.5 \\
9 & $\mathrm{KJ}(\mathrm{Y})$ & 4 & 0.33 \\
10 & $\mathrm{KJ}(\mathrm{N})$ & 8 & 0.67 \\
11 & $\mathrm{OG}(\mathrm{Y})$ & 10 & 0.83 \\
12 & $\mathrm{OG}(\mathrm{N})$ & 2 & 0.17 \\
13 & $\mathrm{OC}(\mathrm{Y})$ & 3 & 0.25
\end{tabular}




\begin{tabular}{cccc}
14 & $\mathrm{OC}(\mathrm{N})$ & 9 & 0.75 \\
15 & $\mathrm{OMP}(\mathrm{Y})$ & 11 & 0.917 \\
16 & $\mathrm{OMP}(\mathrm{N})$ & 1 & 0.083 \\
17 & $\mathrm{KC}(\mathrm{Y})$ & 5 & 0.417 \\
18 & $\mathrm{KC}(\mathrm{N})$ & 7 & 0.583 \\
19 & $\mathrm{BL}(\mathrm{Y})$ & 4 & 0.33 \\
20 & $\mathrm{BL}(\mathrm{N})$ & 8 & 0.67 \\
21 & $\mathrm{OY}(\mathrm{Y})$ & 11 & 0.917 \\
22 & $\mathrm{OY}(\mathrm{N})$ & 1 & 0.083 \\
23 & $\mathrm{~B}(\mathrm{Y})$ & 8 & 0.67 \\
24 & $\mathrm{~B}(\mathrm{~N})$ & 4 & 0.33 \\
25 & $\mathrm{OU}(\mathrm{Y})$ & 1 & 0.083 \\
26 & $\mathrm{OU}(\mathrm{N})$ & 11 & 0.917 \\
27 & $\mathrm{R}(\mathrm{Y})$ & 2 & 0.17 \\
28 & $\mathrm{R}(\mathrm{N})$ & 10 & 0.83 \\
29 & $\mathrm{OS}(\mathrm{Y})$ & 2 & 0.17 \\
30 & $\mathrm{OS}(\mathrm{N})$ & 10 & 0.83 \\
\hline
\end{tabular}

Pada tabel 5 itemset nomor $2\{\mathrm{BD}(\mathrm{N})\}$, nomor $3\{\mathrm{KK}(\mathrm{Y})\}$, nomor $6\{\mathrm{OM}(\mathrm{N})\}$, nomor 7 $\{\mathrm{K}(\mathrm{Y})\}$, nomor $8\{\mathrm{~K}(\mathrm{~N})\}$, nomor $9\{\mathrm{KJ}(\mathrm{Y})\}$, nomor $12\{\mathrm{OG}(\mathrm{N})\}$, nomor $13\{\mathrm{OC}(\mathrm{Y})\}$, nomor 16 $\{\mathrm{OMP}(\mathrm{N})\}$, nomor $17\{\mathrm{KC}(\mathrm{Y})\}$, nomor $19\{\mathrm{BL}(\mathrm{Y})\}$, nomor $22\{\mathrm{OY}(\mathrm{N})\}$, nomor $24\{\mathrm{~B}(\mathrm{~N})\}$, nomor 25 $\{\mathrm{OU}(\mathrm{Y})\}$, nomor $27\{\mathrm{R}(\mathrm{Y})\}$ dan nomor $29\{\mathrm{OS}(\mathrm{Y})\}$ bukan termasuk frequent item, karena tidak memenuhi syarat frequent 1-itemset sehingga tidak termasuk pada tabel F1. Selanjutnya algoritma akan mencari semua transaksi untuk menghitung transaksi penjualan suku cadang motor yang muncul pada setiap item sampai frequent 3-itemset (F3).

Tabel 6. Frequent 3-Itemset

\begin{tabular}{ccccl} 
C3 & \multicolumn{1}{c}{ Itemset } & Frequent Item & Support & Confidence \\
\hline No. & \multicolumn{1}{c}{ C } & 4 & 0.33 & $50 \%$ \\
\hline 1 & $\mathrm{BD}(\mathrm{Y}), \mathrm{OM}(\mathrm{Y}), \mathrm{KJ}(\mathrm{N})$ & 8 & 0.67 & $100 \%$ \\
2 & $\mathrm{BD}(\mathrm{Y}), \mathrm{OM}(\mathrm{Y}), \mathrm{OG}(\mathrm{Y})$ & 5 & 0.417 & $63 \%$ \\
3 & $\mathrm{BD}(\mathrm{Y}), \mathrm{OM}(\mathrm{Y}), \mathrm{OC}(\mathrm{N})$ & 8 & 0.67 & $100 \%$ \\
4 & $\mathrm{BD}(\mathrm{Y}), \mathrm{OM}(\mathrm{Y}), \mathrm{OMP}(\mathrm{Y})$ & 4 & 0.33 & $50 \%$ \\
5 & $\mathrm{BD}(\mathrm{Y}), \mathrm{OM}(\mathrm{Y}), \mathrm{BL}(\mathrm{N})$ & 8 & 0.67 & $100 \%$ \\
6 & $\mathrm{BD}(\mathrm{Y}), \mathrm{OM}(\mathrm{Y}), \mathrm{OY}(\mathrm{Y})$ & 6 & 0.5 & $75 \%$ \\
7 & $\mathrm{BD}(\mathrm{Y}), \mathrm{OM}(\mathrm{Y}), \mathrm{B}(\mathrm{Y})$ & 8 & 0.67 & $100 \%$ \\
8 & $\mathrm{BD}(\mathrm{Y}), \mathrm{OM}(\mathrm{Y}), \mathrm{OU}(\mathrm{N})$ & 6 & 0.5 & $75 \%$ \\
9 & $\mathrm{BD}(\mathrm{Y}), \mathrm{OM}(\mathrm{Y}), \mathrm{R}(\mathrm{N})$ & 7 & 0.583 & $88 \%$ \\
10 & $\mathrm{BD}(\mathrm{Y}), \mathrm{OM}(\mathrm{Y}), \mathrm{OS}(\mathrm{N})$ & 7 & 0.583 & $100 \%$ \\
11 & $\mathrm{KK}(\mathrm{N}), \mathrm{OMP}(\mathrm{Y}), \mathrm{OU}(\mathrm{N})$ & 7 & 0.583 & $100 \%$ \\
12 & $\mathrm{KK}(\mathrm{N}), \mathrm{OMP}(\mathrm{Y}), \mathrm{OS}(\mathrm{N})$ & 8 & 0.67 & $100 \%$ \\
13 & $\mathrm{OM}(\mathrm{Y}), \mathrm{OG}(\mathrm{Y}), \mathrm{OMP}(\mathrm{Y})$ & 8 & 0.67 & $100 \%$ \\
14 & $\mathrm{OM}(\mathrm{Y}), \mathrm{OG}(\mathrm{Y}), \mathrm{OY}(\mathrm{Y})$ & & &
\end{tabular}




\begin{tabular}{|c|c|c|c|c|}
\hline 15 & $\mathrm{OM}(\mathrm{Y}), \mathrm{OG}(\mathrm{Y}), \mathrm{OU}(\mathrm{N})$ & 8 & 0.67 & $100 \%$ \\
\hline 16 & $\mathrm{OM}(\mathrm{Y}), \mathrm{OG}(\mathrm{Y}), \mathrm{OS}(\mathrm{N})$ & 7 & 0.583 & $88 \%$ \\
\hline 17 & $\mathrm{KJ}(\mathrm{N}), \mathrm{OC}(\mathrm{N}), \mathrm{OMP}(\mathrm{Y})$ & 8 & 0.67 & $100 \%$ \\
\hline 18 & $\mathrm{KJ}(\mathrm{N}), \mathrm{OC}(\mathrm{N}), \mathrm{OY}(\mathrm{Y})$ & 7 & 0.583 & $88 \%$ \\
\hline 19 & $\mathrm{KJ}(\mathrm{N}), \mathrm{OC}(\mathrm{N}), \mathrm{OU}(\mathrm{N})$ & 7 & 0.583 & $88 \%$ \\
\hline 20 & $\mathrm{KJ}(\mathrm{N}), \mathrm{OC}(\mathrm{N}), \mathrm{R}(\mathrm{N})$ & 7 & 0.583 & $88 \%$ \\
\hline 21 & $\mathrm{KJ}(\mathrm{N}), \mathrm{OC}(\mathrm{N}), \mathrm{OS}(\mathrm{N})$ & 7 & 0.583 & $88 \%$ \\
\hline 22 & $\mathrm{OG}(\mathrm{Y}), \mathrm{OC}(\mathrm{N}), \mathrm{OMP}(\mathrm{Y})$ & 7 & 0.583 & $100 \%$ \\
\hline 23 & $\mathrm{OG}(\mathrm{Y}), \mathrm{OC}(\mathrm{N}), \mathrm{OY}(\mathrm{Y})$ & 7 & 0.583 & $100 \%$ \\
\hline 24 & $\mathrm{OG}(\mathrm{Y}), \mathrm{OC}(\mathrm{N}), \mathrm{B}(\mathrm{Y})$ & 6 & 0.5 & $86 \%$ \\
\hline 25 & $\mathrm{OG}(\mathrm{Y}), \mathrm{OC}(\mathrm{N}), \mathrm{OU}(\mathrm{N})$ & 6 & 0.5 & $86 \%$ \\
\hline 26 & $\mathrm{OG}(\mathrm{Y}), \mathrm{OC}(\mathrm{N}), \mathrm{R}(\mathrm{N})$ & 5 & 0.417 & $71 \%$ \\
\hline 27 & $\mathrm{OG}(\mathrm{Y}), \mathrm{OC}(\mathrm{N}), \mathrm{OS}(\mathrm{N})$ & 5 & 0.417 & $71 \%$ \\
\hline 28 & $\mathrm{OC}(\mathrm{N}), \mathrm{OY}(\mathrm{Y}), \mathrm{B}(\mathrm{Y})$ & 7 & 0.583 & $88 \%$ \\
\hline 29 & $\mathrm{OC}(\mathrm{N}), \mathrm{OY}(\mathrm{Y}), \mathrm{OU}(\mathrm{N})$ & 7 & 0.583 & $88 \%$ \\
\hline 30 & $\mathrm{OC}(\mathrm{N}), \mathrm{OY}(\mathrm{Y}), \mathrm{R}(\mathrm{N})$ & 6 & 0.5 & $75 \%$ \\
\hline 31 & $\mathrm{OC}(\mathrm{N}), \mathrm{OY}(\mathrm{Y}), \mathrm{OS}(\mathrm{N})$ & 6 & 0.5 & $75 \%$ \\
\hline 32 & $\mathrm{OMP}(\mathrm{Y}), \mathrm{KC}(\mathrm{N}), \mathrm{BL}(\mathrm{N})$ & 6 & 0.5 & $86 \%$ \\
\hline 33 & $\mathrm{OMP}(\mathrm{Y}), \mathrm{KC}(\mathrm{N}), \mathrm{OY}(\mathrm{Y})$ & 6 & 0.5 & $86 \%$ \\
\hline 34 & $\mathrm{OMP}(\mathrm{Y}), \mathrm{KC}(\mathrm{N}), \mathrm{B}(\mathrm{Y})$ & 4 & 0.33 & $57 \%$ \\
\hline 35 & $\mathrm{OMP}(\mathrm{Y}), \mathrm{KC}(\mathrm{N}), \mathrm{OU}(\mathrm{N})$ & 6 & 0.5 & $86 \%$ \\
\hline 36 & $\mathrm{OMP}(\mathrm{Y}), \mathrm{KC}(\mathrm{N}), \mathrm{R}(\mathrm{N})$ & 7 & 0.583 & $100 \%$ \\
\hline 37 & $\mathrm{OMP}(\mathrm{Y}), \mathrm{KC}(\mathrm{N}), \mathrm{OS}(\mathrm{N})$ & 6 & 0.5 & $86 \%$ \\
\hline 38 & $\mathrm{KC}(\mathrm{N}), \mathrm{R}(\mathrm{N}), \mathrm{OS}(\mathrm{N})$ & 6 & 0.5 & $86 \%$ \\
\hline 39 & $\mathrm{BL}(\mathrm{N}), \mathrm{OY}(\mathrm{Y}), \mathrm{OU}(\mathrm{N})$ & 6 & 0.5 & $86 \%$ \\
\hline 40 & $\mathrm{BL}(\mathrm{N}), \mathrm{OY}(\mathrm{Y}), \mathrm{R}(\mathrm{N})$ & 7 & 0.583 & $100 \%$ \\
\hline 41 & $\mathrm{OY}(\mathrm{Y}), \mathrm{B}(\mathrm{Y}), \mathrm{OU}(\mathrm{N})$ & 7 & 0.583 & $88 \%$ \\
\hline 42 & $\mathrm{OY}(\mathrm{Y}), \mathrm{B}(\mathrm{Y}), \mathrm{R}(\mathrm{N})$ & 6 & 0.5 & $75 \%$ \\
\hline 43 & $\mathrm{OY}(\mathrm{Y}), \mathrm{B}(\mathrm{Y}), \mathrm{OS}(\mathrm{N})$ & 6 & 0.5 & $75 \%$ \\
\hline 44 & $\mathrm{~B}(\mathrm{Y}), \mathrm{OU}(\mathrm{N}), \mathrm{R}(\mathrm{N})$ & 4 & 0.33 & $57 \%$ \\
\hline 45 & $\mathrm{OU}(\mathrm{N}), \mathrm{R}(\mathrm{N}), \mathrm{OS}(\mathrm{N})$ & 9 & 0.75 & $100 \%$ \\
\hline
\end{tabular}

Dari tabel 6 di atas kandidat C3 dari frequent 3-itemset, terdapat 45 pasang itemset. Dan yang hanya memenuhi syarat minimum support dan minimum confidence 15 itemset yang terbentuk. Dengan munculnya frequent 3- itemset $(\mathrm{F} 3)$ tersebut maka calon aturan assosiasi dengan 2 antecedent yang memenuhi syarat mincoft $90 \%$.

\subsubsection{Pengujian Menggunakan WEKA}

1) Sebelum data diolah menggunakan WEKA, maka salin data penjualan suku cadang motor pada MS.Excel terlebih dahulu. 


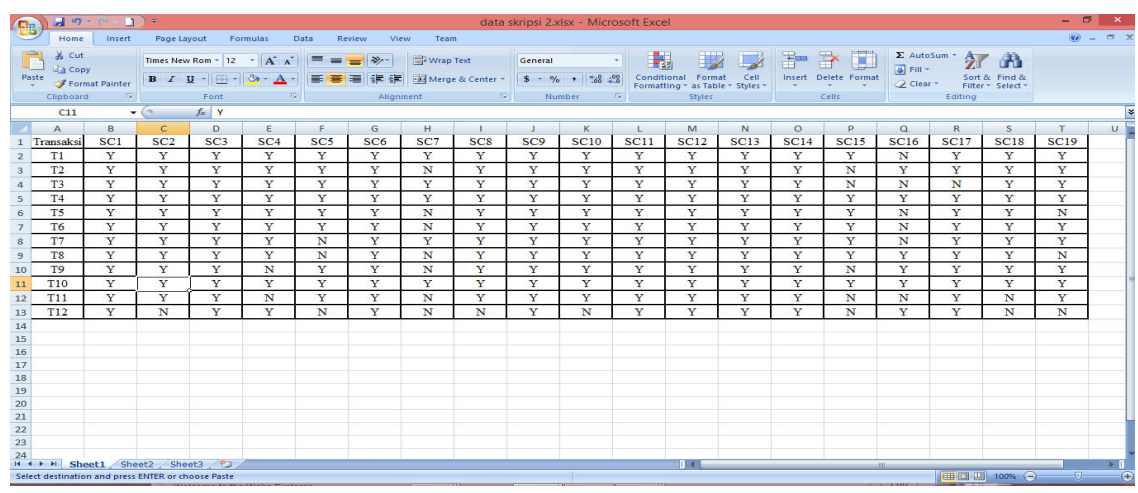

2) Buka aplikasi WEKA, kemudian klik menu "explore".

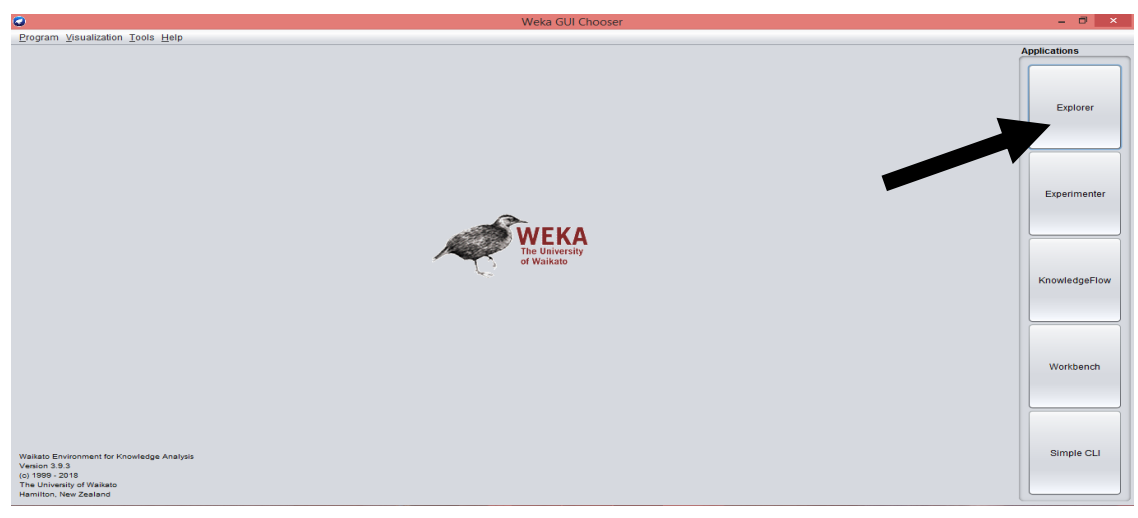

3) Setelah muncul tampilan seperti gambar yang dibawah ini, pilih type data yang kita gunakan, type data yang dipakai adalah CSV.

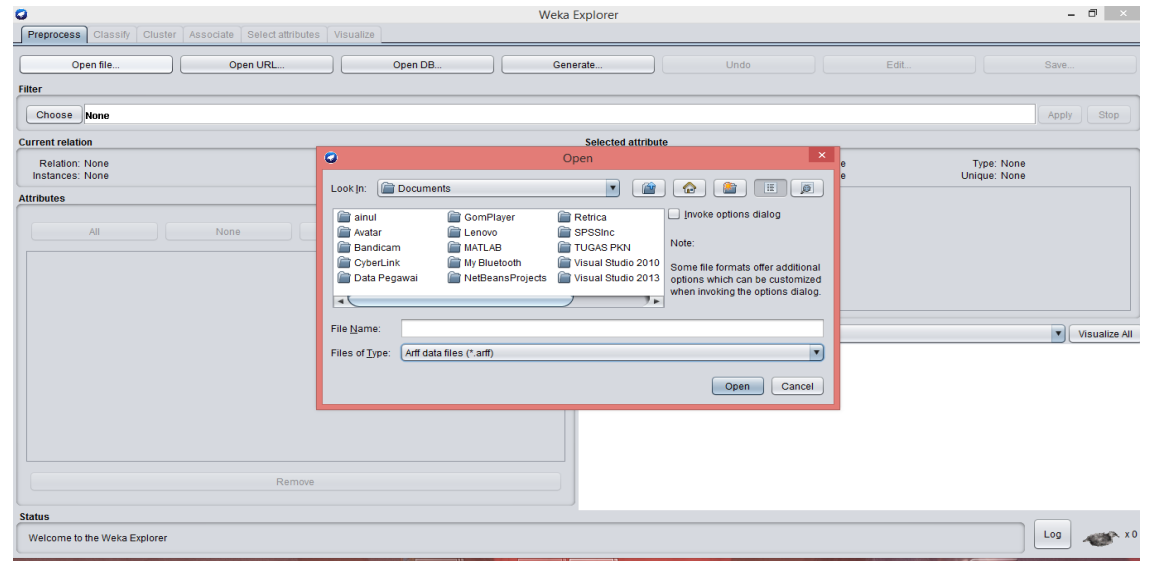

4) Lalu hasil dari pengolahan data tersebut akan tampil seperti pada gambar di bawah ini. 


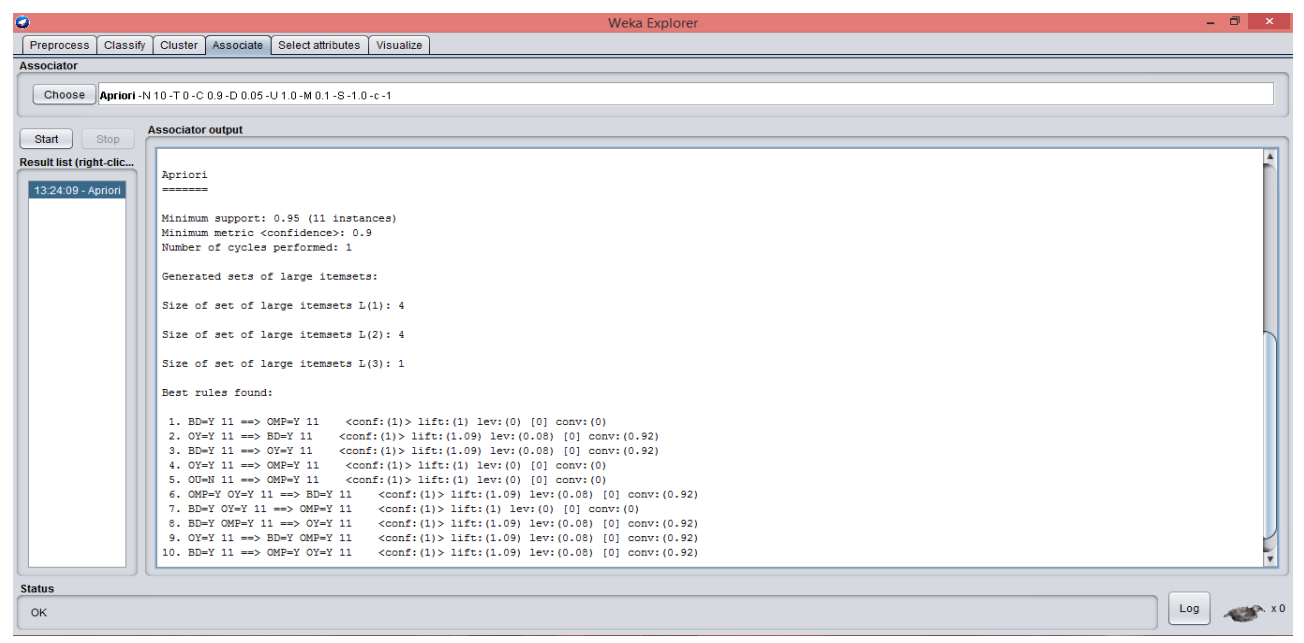

\section{Kesimpulan}

Data mining Algoritma apriori dapat digunakan untuk mengolah data hasil transaksi penjualan suku cadang motor pada bengkel Candra Motor, sehingga dapat menentukan rule asosiasi antar barang yang terjual sehingga memudahkan pengguna jumlah barang yang terjual. Data mining algoritma apriori memberikan keputan yang tepat pengolahan data secara manual maupun menggunakan software WEKA 3.9, maka suku cadang motor yang paling banyak terjual adalah ban dalam, oli Yamaha, dan oli MPX dengan nilai minimum support $90 \%$ dan minimum confidence $100 \%$.

\section{Daftar Pustaka}

[1] D. S. Purnia and A. I. Warnilah, "Implementasi Data Mining Pada Penjualan Kacamata Menggunakan Algoritma Apriori," vol. 2, no. 2, pp. 31-39, 2017.

[2] A. H. Elyas and J. Prayoga, "Implementasi Data Mining Pola penjualan Sparepart Motor Honda Pada Pt Rotella Persada Mandiri Dengan Menggunakan Algoritma Apriori," vol. 1, no. 1, pp. 22-31, 2020.

[3] Y. Yulia and N. Azwanti, "Penerapan Algoritma C4.5 Untuk Memprediksi Besarnya Penggunaan Listrik Rumah Tangga di Kota Batam," Resti, vol. 2, no. 2, pp. 584-590, 2018.

[4] E. Buulolo, "Implementasi Algoritma Apriori Pada Sistem Persediaan Obat ( Studi Kasus : Apotik Rumah Sakit Estomihi Medan )," pp. 71-83, 2013.

[5] R. Yanto and R. Khoiriah, "Implementasi Data Mining dengan Metode Algoritma Apriori dalam Menentukan Pola Pembelian Obat," pp. 102-113, 2015.

[6] S. B. A. Saputra, R. Dwiana, W. D. N. Oktaviani, R. D. Isnaeni', T. Astuti, and Nurfaizah, "Implementasi Data Mining Algoritme Apriori pada Penjualan Suku Cadang Motor Delta Motor," Citisee, pp. 108-113, 2016.

[7] R. Ristianinggrum and S. Sulatri, "Implementasi data mining menggunakan algoritma apriori 1,2," Pros. SINTAK, pp. 372-382, 2017.

[8] Sugiyono, No Title. 2014.

[9] J. L. Putra et al., "IMPLEMENTASI ALGORITMA APRIORI TERHADAP DATA PENJUALAN," vol. 15, no. 1, pp. 85-90, 2019.

[10] H. Kusumo, E. Sediyono, and M. Marwata, "Analisis Algoritma Apriori Untuk Mendukung Strategi Promosi Perguruan Tinggi," vol. 1, no. 1, pp. 51-62, 2019.

[11] M. P. Tana, F. Marisa, I. D. Wijaya, J. T. Informatika, and F. T. U. Widyagama, "Penerapan Metode Data Mining Market Basket Analysis Terhadap Data Penjualan Produk Pada Toko Oase Menggunakan Algoritma Apriori," vol. 3, no. 2, pp. 17-22, 2018. 